\title{
Fricke and polymer gel 2D dosimetry validation using Monte Carlo simulation
}

\author{
J. Vedelago ${ }^{\text {a, b }}$, D. Chacón Obando ${ }^{\text {a, c }}$, F. Malano ${ }^{\text {a, b }}$, R. Conejeros ${ }^{\text {d }}$, R. Figueroa ${ }^{\text {e }}$, \\ D. Garcia ${ }^{\text {f }}$, G. González ${ }^{\text {f }}$, M. Romero ${ }^{\text {a, g }}$, M. Santibañez ${ }^{\text {e }}$, M.C. Strumia ${ }^{g}$, J. Velásquez ${ }^{\text {d }}$, \\ F. Mattea ${ }^{\text {a, h, * }}$, M. Valente ${ }^{\text {b, a, e, }{ }^{* *}}$ \\ ${ }^{a}$ Laboratory for Research and Instrumentation in Physics Applied to Medicine and X-Ray Imaging (LIIFAMIR ${ }^{x}$, National University of Córdoba, Córdoba, \\ Argentina \\ b Institute of Physics Enrique Gaviola - CONICET, Argentina \\ ${ }^{c}$ Physics Department, Universidad Nacional (UNA), Heredia, Costa Rica \\ ${ }^{\mathrm{d}}$ Servicio de Radioterapia, ICOS, Temuco, Chile \\ e Departamento de Ciencias Físicas, Universidad de La Frontera, Temuco, Chile \\ f Servicio de Imágenes por Resonancia Magnética, ICOS, Temuco, Chile \\ ${ }^{\mathrm{g}}$ National University of Córdoba and Institute for Multidisciplinary Plant Biology - CONICET, Argentina \\ ${ }^{\mathrm{h}}$ Department of Organic Chemistry, Faculty of Chemical Sciences, National University of Córdoba and CONICET, Argentina
}

\section{H I G H L I G H T S}

- Fricke and NIPAM gel dosimetry are tested in conformal radiotherapy.

- Rigorous (1 mm-2\%) Gamma test in 1D and 2D are performed for cross-comparisons.

- Very good agreements with TPS and MC simulations was obtained for gel dosimeters.

- Results suggest promising performance for quality assurance in radiotherapy.

\section{A R T I C L E I N F O}

\section{Article history:}

Received 24 September 2015

Received in revised form

16 May 2016

Accepted 20 May 2016

Available online 24 May 2016

\section{Keywords:}

Gel dosimetry

Quality assurance

Gamma index

Monte Carlo simulation

Fricke gel

\begin{abstract}
A B S T R A C T
Complexity in modern radiotherapy treatments demands advanced dosimetry systems for quality control. These systems must have several characteristics, such as high spatial resolution, tissue equivalence, three-dimensional resolution, and dose-integrating capabilities. In this scenario, gel dosimetry has proved to be a very promising option for quality assurance. In this study, the feasibility of Fricke and polymer gel dosimeters suitably shaped in form of thin layers and optically analyzed by visible light transmission imaging has been investigated for quality assurance in external radiotherapy. Dosimeter irradiation was carried out with a 6-MV photon beam (CLINAC 600C). The analysis of the irradiated dosimeters was done using two-dimensional optical transmission images. These dosimeters were compared with a treatment plan system using Monte Carlo simulations as a reference by means of a gamma test with parameters of $1 \mathrm{~mm}$ and $2 \%$. Results show very good agreement between the different dosimetric systems: in the worst-case scenario, $98 \%$ of the analyzed points meet the test quality requirements. Therefore, gel dosimetry may be considered as a potential tool for the validation of other dosimetric systems.
\end{abstract}

() 2016 Elsevier Ltd. All rights reserved.

\footnotetext{
* Corresponding author. Department of Organic Chemistry, Faculty of Chemical Sciences, National University of Córdoba and CONICET, Argentina.

** Corresponding author. Institute of Physics Enrique Gaviola - CONICET, Argentina.

E-mail addresses: jvedelago@famaf.unc.edu.ar (J. Vedelago), fmattea@gmail.com (F. Mattea), valente@famaf.unc.edu.ar (M. Valente).

URL: http://liifamirx.famaf.unc.edu.ar/members/vedelago/
}

\section{Introduction}

The increasing complexity of dose delivery techniques in modern radiotherapy treatments demands the use of quality control procedures with high spatial resolution, three-dimensional (3D) capabilities, dose-integrating characteristics, and tissue 
equivalence (Knöös, 2015). Many systems have been proposed aiming to fulfill those needs, among them gel dosimeters, which are mainly analyzed by magnetic resonance imaging (da Silveira et al., 2014; Ceberg et al., 2010), optical readings (Vanossi et al., 2008; Chang et al., 2014), or X-ray computed tomography (X-ray CT) scanning (Jirasek et al., 2010; Chiu et al., 2014).

Two well-known types of gel dosimeters were used in this study: Fricke gel dosimeters (Schreiner, 2004) doped with benzoic acid (BFGD) (Gupta and Gomathy, 1974) and polymer gel dosimeters based on N-isopropylacrylamide and N,N'methylenebis(acrylamide) (NIPAM) (Chang et al., 2011).

Fricke gel dosimeters are mainly a gel matrix containing ferrous sulfate $\left(\mathrm{Fe}^{+2}\right)$ that, when exposed to ionizing radiation, are oxidized to ferric sulfate $\left(\mathrm{Fe}^{+3}\right)$ at a rate proportional to the absorbed dose (Schreiner, 2004). When combined with an adequate colorant such as xylenol orange, these systems are suitable for optical transmission readings of the sensitive material (Kelly et al., 1998).

Alternatively, polymer gel dosimeters are able to register and quantify the absorbed dose because of the formation of crosslinked networks, usually referred to as hydrogels (Baldock et al., 2010). No colorant is required for these materials, because the hydrogel formation already produces density changes, related to the ionizing radiation exposure of the sensitive material, large enough to be detected by optical transmission methods (Wuu and $\mathrm{Xu}, 2011$ ). One of the main advantages of polymer gel dosimeters over Fricke gel dosimeters is the preservation of the information over time after the irradiation. In addition, diffusion of $\mathrm{Fe}^{+3}$ ions is a well-known limitation for Fricke gel dosimetry that must be overcome with a prompt sample reading after the irradiation (Vedelago et al., 2014; Harris et al., 1996; Baldock et al., 2001). By contrast, polymer gel dosimeters have the disadvantage of requiring more toxic materials in the manufacturing process (Maryanski et al., 1994; Senden et al., 2006).

Film dosimetry is a widely disseminated technique for radiotherapy commissioning. Radiochromic films emerged as a valuable option for dose measurements in photon fields, because of their high spatial resolution, near-tissue equivalence, and low energy dependence (Huet et al., 2012). However, radiochromic film dosimeters present some drawbacks such as the dependence of their absorption peak with temperature, postirradiation time for optical density buildup, and the dependence on light source polarization of the readout system (Devic, 2011). Gel dosimeters in layer shapes and radiochromic films have similar radiological characteristics, but with the former ones, it is relatively simple to obtain a 3D reconstruction of the absorbed dose. Furthermore, with gel dosimetry, it is possible to have a continuous 3D detection volume. An excellent agreement among these types of dosimeters has been reported in the literature (De Deene et al., 1998; Hassani et al., 2014) with the exception of measurements in the penumbra regions.

In this study, both BFGD and NIPAM dosimeters were optically analyzed from bidimensional optical transmission measurements by capturing images with a charge-coupled device camera provided with suitable monochromatic filters corresponding to the absorbance peak of each gel dosimeter (580 nm for BFGD and $430 \mathrm{~nm}$ for NIPAM).

In order to check the reliability of the external beam radiotherapy treatments used with patients, the treatment planning system (TPS) dose calculations were compared with the gel dosimetry experimental measurements using Monte Carlo (MC) simulations as a reference in both cases. Modern TPS software systems are based on pencil-beam dose calculations (Knöös et al., 1994) on a patient's anatomy obtained by means of X-ray CT.

Another important dose calculation method is MC simulation (Spezi et al., 2002; Kairn et al., 2012). Furthermore, validated MC simulations can be used as a reference method for other dosimetric systems. Dose calculations obtained from simulation methods are useful for some particular estimations, such as scattering contributions or tissue equivalence studies (Keall and Baldock, 1999), but experimental measurements are still essential to obtain physical validations of the simulations results (Mariani et al., 2007). In order to perform an exhaustive quantification and comparison, MC PENELOPE code (Baró et al., 1995) was used to reproduce dosimeter irradiation.

The aim of this study is to assess the gel dosimetry capabilities for quality assurance (QA) in external photon beam radiation treatments. Gamma index (Low et al., 1998) calculations between dose distributions were made to obtain a quantitative comparison between the different methods. A further intent of this study is to promote the use of gel dosimetry as a valuable tool for QA routines commonly used in the clinical field, such as electronic portal imaging device (EPID) (Deshpande et al., 2011) or ionization chamber arrays (Poppe et al., 2006).

\section{Materials and methods}

\subsection{Gel dosimeters}

The two types of gel dosimeters used in this study were prepared using Milli-Q water and gelatin from porcine skin, type A 300 Bloom.

\subsubsection{Benzoic fricke gel dosimeter}

The BFGD sensitive material was manufactured based on the method described elsewhere (Gupta and Gomathy, 1974). Benzoic acid $(0.29 \% \mathrm{w} / \mathrm{w})$ was dissolved at $60{ }^{\circ} \mathrm{C}$ in the entire volume of water with constant stirring for approximately $15 \mathrm{~min}$. Gelatin 300 Bloom $(3.00 \% \mathrm{w} / \mathrm{w})$ was then incorporated into half of the benzoic acid solution and stirred for $20 \mathrm{~min}$ at $50^{\circ} \mathrm{C}$. Next, the resulting gel matrix was mixed with the rest of the solution at $28{ }^{\circ} \mathrm{C}$. Then, sulfuric acid $(1.38 \% \mathrm{w} / \mathrm{w})$, xylenol orange $(0.04 \% \mathrm{w} / \mathrm{w})$, and ferrous sulfate $(0.06 \% \mathrm{w} / \mathrm{w})$ were added and stirred until a homogeneous solution was obtained. Finally, glutaraldehyde $(0.23 \% \mathrm{w} / \mathrm{w})$ was added to the solution.

Layer-type containers were filled with the final solution and properly sealed to avoid the presence of oxygen in the dosimeters during their storage and irradiation and postirradiation analyses. These materials were stored at $4{ }^{\circ} \mathrm{C}$ without exposure to light for at least $12 \mathrm{~h}$ before irradiation. The same storage conditions were maintained after their irradiation until the materials were analyzed. Ferrous sulfate and benzoic acid were provided by Research AG, (Buenos Aires, ARG).

\subsubsection{NIPAM polymer gel dosimeter}

The NIPAM sensitive material was prepared with $\mathrm{N}$-isopropylacrylamide (97\%) and N,N'-methylenebis(acrylamide) (99\%). The manufacture protocol used in this study has been described elsewhere (Mattea et al., 2013). Briefly, the gelatin 300 Bloom $(5.00 \% \mathrm{w} / \mathrm{w})$ was dissolved at room temperature and then heated to $50{ }^{\circ} \mathrm{C}$. After 30 -min stirring, the temperature reduced to $37^{\circ} \mathrm{C}$ and the $\mathrm{N}, \mathrm{N}$ '-methylenebis(acrylamide) $(3.00 \% \mathrm{w} / \mathrm{w})$ was mixed in. Then, the $\mathrm{N}$-isopropylacrylamide $(5.00 \% \mathrm{w} / \mathrm{w})$ was added and stirred until a homogeneous mixture was achieved. Tetrakis(hydroxymethyl)phosphonium chloride (THPC) was added to the mixture as oxygen scavenger and the whole solution was stirred for $30 \mathrm{~min}$ at $37{ }^{\circ} \mathrm{C}$ to obtain a THPC final concentration of $5 \mathrm{mM}$. Finally, glutaraldehyde $(0.23 \% \mathrm{w} / \mathrm{w})$ was added to the solution to improve the stability of the gel matrix in the dosimeters with temperature. The whole process was done in a sealed vessel where special care was taken to avoid the presence of oxygen in the solution. This solution was used to fill layer-type containers and the 
manufactured dosimeters were stored at $4{ }^{\circ} \mathrm{C}$ for at least $24 \mathrm{~h}$ before irradiation. The same care was taken in the pre- and postirradiation intervals to avoid oxygen or light effects on the dosimeters. The rest of the reagents used in this study were provided by Sigma-Aldrich ${ }^{\circledR}$ (Saint Louis, MO, USA) and used without further processing.

\subsubsection{Optical analysis}

The gel dosimeter containers were specifically designed with a layer shape to optimize their optical analysis (Valente et al., 2007; Gambarini et al., 2007). An apparatus with a homogeneous light source and charge-coupled device (CCD) camera SXV-H5 (Starlight Xpress Ltd, Binfield, UK) coupled with suitable optical filters, $580 \mathrm{~nm}$ P/N: $580 \mathrm{FS} 10-25$ for BFGD and $430 \mathrm{~nm}$ P/N: 430FS10-25 (Andover Corporation, Salem, NH, USA) for NIPAM, was used to acquire transmission images before and after each sample irradiation. In this apparatus, the CCD camera was controlled through a USB port and the transmission images were recorded in gray-level maps for further analysis. A spatial resolution of $3.74 \pm 0.01$ pixels/ $\mathrm{mm}$ and an overall reproducibility of not less than $99 \%$ can be obtained with this setup.

Transmission images were taken before $I_{b}$ and after irradiation $I_{a}$.From these images, optical density changes $(\Delta O D)$ were calculated, which are linearly correlated to the absorbed dose $D$ by the expression:

$D=\alpha \Delta O D=\alpha \log _{10}\left(I_{b} / I_{a}\right)$

where $\alpha$ represents a calibration factor. A thorough description of the apparatus and analytical method has been presented elsewhere. (Valente and Vedelago, 2013)

\subsection{Treatment planning system}

A linear accelerator from Varian Medical Systems Inc. (Palo Alto, CA, USA). (CLINAC 600C) was used for the irradiation experiments. PCRT 3D (v6.0.2.12) software was used for the treatment planning using the Clarkson-3D calculation method. In order to imitate a typical clinical case, a CT scan of the phantom was performed with a SIEMENS AG (Munich, GER) Biograph TruePoint PET-CT. The CT spatial resolution was $1.3 \times 1.3 \times 3.0 \mathrm{~mm}^{3}$.

For gel dosimeter irradiation, layer-type containers of $10 \times 10 \times 0.3 \mathrm{~cm}^{3}$ were used inside a cubic phantom with inner dimensions of $10 \times 10 \times 10 \mathrm{~cm}^{3}$ and wall thickness of $1.2 \mathrm{~cm}$. The material of all the containers and phantoms was poly(methylmethacrylate) (PMMA).

A four-field-box isocentric technique (Valente et al., 2007), consisting of two pairs of parallel and opposite fields, was implemented to achieve a symmetric dose geometry. Each field size (FS) was set to $30 \times 30 \mathrm{~mm}^{2}$ at the phantom's surface, and a source-tosurface distance (SSD) of $94 \mathrm{~cm}$ was chosen. An absolute dose of $12 \mathrm{~Gy}$ in the isocenter was selected, resulting in 486 monitor units (MU) per field. A dose rate of $320 \mathrm{MU} / \mathrm{min}$ was used in all the experiments.

\subsection{MC simulations}

The PENELOPE system code (version 2011) was used to perform the MC simulations (Baró et al., 1995) in this study. This code has been used and described extensively in numerous studies involving electron-photon transport and has been thoroughly validated against experimental data (Sempau et al., 2003).

The simulation geometry was built from 3D information contained in the tomographic images of the phantoms. This geometry was segmented in voxels containing either air, water, or PMMA, according to their Hounsfield index. The size of the voxels was defined with the sizes of the DICOM Image's metadata $\left(1.3 \times 1.3 \times 3 \mathrm{~mm}^{3}\right)$.

The irradiation setup already described for the TPS method was selected. For that purpose, an isotropic point radiation source placed at a distance of $100 \mathrm{~cm}$ from the phantom's center and aligned to it was used, and the final SSD was $94 \mathrm{~cm}$. A squareshaped collimator was placed on the phantom's surface to obtain an FS of $3 \times 3 \mathrm{~cm}^{2}$. The emission spectrum of the source was established from available estimations (Mohan et al., 1985) corresponding to a Varian Clinac-6 accelerator at $6 \mathrm{MV}$.

The simulations were performed with a number of showers high enough (at least $1 \times 10^{9}$ primary particles) to verify that the uncertainty on the dose in the voxels placed on the phantom's symmetry axis is $<2 \%$. The remaining simulation parameters were set to reduce the calculation time without diminishing the quality of the simulation outcomes. A full description of the simulation parameters and methodology followed in this study has been found elsewhere (Sempau and Andreo, 2006). The simulations were carried out with a CPU of Intel ${ }^{\circledR}$ Core ${ }^{\text {TM }}$ i 950, 3.07 Ghz with 4 Gb RAM and Linux Kernel 2.6.32 64 bit.

In order to validate the MC simulations, a simple irradiation configuration was simulated and compared with the experimental data. These data were recorded on a Classic Farmer-type ionization chamber Exradin A16 in a water phantom. The percentage depth dose (PDD) of MC and ionization chamber were compared for two different FZs: $10 \times 10 \mathrm{~cm}^{2}$ and $3 \times 3 \mathrm{~cm}^{2}$.

\subsection{Comparison method}

For data manipulation, comparison, and visualization, a group of algorithms was developed using MATLAB $^{\circledR}$ version 7.11.0.584 (R2010b) 64 bit (MathWorks Inc, Natick, MA, USA). A section of this code was dedicated to gamma index calculations, which is considered an excellent tool to compare dose distributions measured or calculated from different methods. In this study, MC dose information was used as the reference dose distribution for gamma calculations. Each gamma analysis was carried out normalizing the test distribution with the distribution selected as reference, for example, for the BFGD versus MC gamma analysis, both dose distributions were normalized to 12 Gy given by the MC simulation. Nevertheless, some direct comparisons between both gel dosimeter results were included. The parameters for the gamma calculations were selected in agreement with the precision and accuracy of the different measurement and calculation methods used in this study. Therefore, all gamma calculations were performed using a distance to agreement (DTA) of $1 \mathrm{~mm}$ and dose difference (DD) of $2 \%$.

Low et al (Low et al., 1998). defined the gamma index $\gamma$ for a specific point $\boldsymbol{r}_{i}$ and a predefined DD $\Delta D_{i}$ as

$\gamma\left(\boldsymbol{r}_{i}\right)=\min \left\{\sqrt{\left(\frac{\left\|\boldsymbol{r}_{i}-\boldsymbol{r}\right\|}{\Delta d}\right)^{2}+\left(\frac{D\left(\boldsymbol{r}_{i}\right)-D(\boldsymbol{r})}{\Delta D_{i}}\right)^{2}}\right\}$ for all $\boldsymbol{r}$,

where $\boldsymbol{r}$ is the spatial coordinate in the dimensions of interest (1D, $2 \mathrm{D}$, or $3 \mathrm{D}$ ) in the analysis, $\boldsymbol{r}_{i}-\boldsymbol{r}$ is the spatial distance between the points $\boldsymbol{r}_{i}$ and $\boldsymbol{r}, \Delta d$ is the DTA, and $D(\boldsymbol{r})$ is the dose value at $\boldsymbol{r}$. Any point with $\gamma<1$ satisfies the passing criterion of this method. For every studied case in this study, a local criterion was adopted for the dose tolerance calculation. It is worth mentioning that using the gamma test in a two-dimensional (2D) analysis will end up in the same or a higher number of points that satisfies the passing criterion than in the one-dimensional (1D) test. Using the same arguments, a 3D gamma test will result in the same or a higher number 
of points that satisfies the passing criterion than in the 2D case.

Gel dosimeters have volumetric dose determination capabilities (Baldock et al., 2010). As a consequence, 3D QA to validate TPS could also be performed. In these cases, 3D gamma index formulation represents an excellent method for evaluating the absorbed dose distribution (Wendling et al., 2007).

\section{Results and discussion}

\subsection{Validation of the MC simulations}

Ionization chamber measurements were taken with a resolution step of $0.5 \mathrm{~mm}$; however, only some points are shown in Fig. 1 for visualization reasons. Ionization chamber experimental uncertainties were below $1 \%$ for every measurement. As can be observed in Fig. 1, there is an excellent agreement between experimental and simulated PDD profiles.

In order to obtain a quantitative comparison between the different profiles, the mean squared relative error (MSRE) was calculated according to the following expression:

MSRE $=\frac{1}{n} \sum_{i=1}^{n}\left(\frac{P D D_{M C}(i)-P D D_{\text {ion. chamber }}(i)}{P D D_{\text {ion. chamber }}(i)}\right)^{2}$

The MSRE s obtained in the simulations with FSs of $10 \times 10 \mathrm{~cm}^{2}$ and $3 \times 3 \mathrm{~cm}^{2}$ were $8 \times 10^{-3} \%$ and $3 \times 10^{-3} \%$, respectively, for a number of experimental points $(n=500)$ in both cases. These results prove and confirm the agreement between MC simulations and the experimental data.

This figure also shows that the scattering contribution for a larger FS is higher, resulting in a higher percentage of the dose for depths higher than $15 \mathrm{~mm}$.

\section{2. $2 D$ dose distributions}

The relative dose distributions in the central plane of the phantom for the four dosimetric systems, TPS, MC simulation, BFGD, and NIPAM, are shown in Fig. 2. Each dose distribution was normalized to their maximum dose ( $12 \mathrm{~Gy})$; therefore, the relative color scales for the four images are the same. This normalization can be done because the dose response curve for the experimental

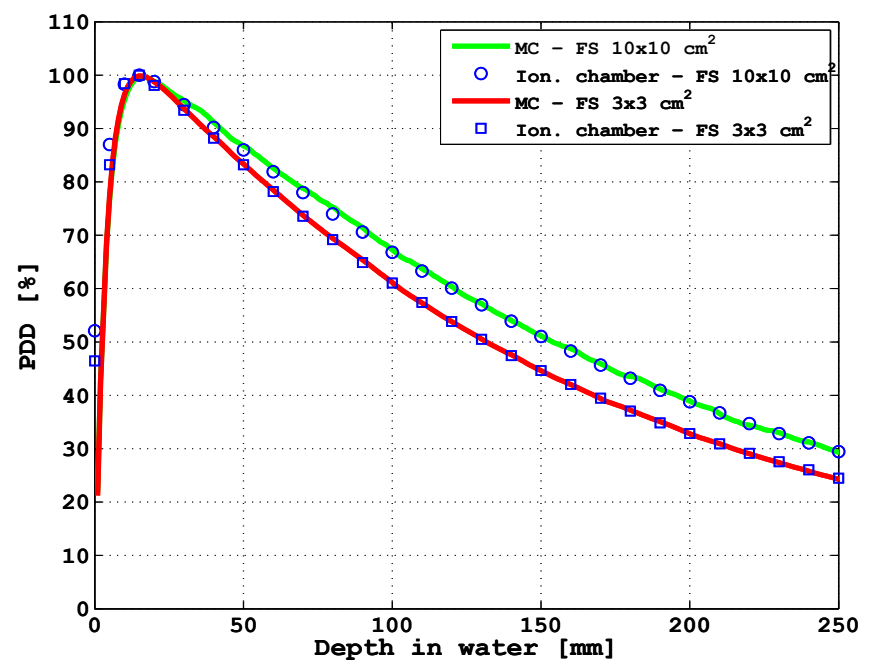

Fig. 1. Monte Carlo simulations and ionization chamber measurements of PDD profiles. MSRE (FS $\left.10 \times 10 \mathrm{~cm}^{2}\right)=8 \times 10^{-3} \%$, MSRE $\left(\right.$ FS $\left.3 \times 3 \mathrm{~cm}^{2}\right)=3 \times 10^{-3} \%$. systems (BFGD and NIPAM dosimeters) presented a linear behavior between 2 and $20 \mathrm{~Gy}$. Initially, there is a correspondence between the dose distributions of the different dosimetric systems. Nonetheless, a quantitative analysis is necessary to provide a better interpretation of the results.

Other authors (Yao et al., 2013) used a similar irradiation configuration, but a comparison of BFGD and MC simulations was not studied.

\subsection{2 gamma test}

For quantification purposes, a 2D gamma analysis was performed considering the MC dose distribution as the reference data. Results are depicted in Fig. 3. With the aim of providing more information than just the rejected or accepted points, gamma indices $<1$ were represented in a black-to-green scale, and the rejected points were represented in red.

It should be mentioned that the layer-type dosimeter containers of $10 \times 10 \mathrm{~cm}^{2}$ have only a useful sensitive area of $7 \times 7 \mathrm{~cm}^{2}$ because of the their sealing methods (parafilm was used to seal containers to prevent sensitive material oxygen contamination). These nonsuitable regions can be observed in dark blue areas in the relative dose distribution of Fig. 2 and in red areas in the borders of both gel dosimeter gamma distributions presented in Fig. 3.

Regarding only the useful sensitive area of the gel dosimeters, the percentages of points in these regions that meet the passing criterion are $98.28 \%$ for BFGD, $99.29 \%$ for NIPAM, and $99.62 \%$ for TPS. As expected, a better agreement was obtained for the comparison of TPS and MC, because for both cases only calculated data were used.

In every case, points that do not meet the passing criterion correspond to high-gradient dose regions, where tolerances could be raised as has been done by other authors (Depuydt et al., 2002). It is worth mentioning that for typical clinical uses where DTA and DD are usually set to $3 \mathrm{~mm}$ and 3\%, respectively, every point studied in the four dosimeters passes the gamma criterion. Moreover, a thorough analysis of the gamma index parameters is presented in Section 3.7. The red regions of BFGD and NIPAM versus MC 2D gamma test presented in Fig. 3 indicate an asymmetry in both gel dosimeter measurements. This behavior is discussed in the "Onaxis Gamma analysis" section.

Furthermore, in order to compare the two gel dosimetry measurements, a 2D gamma test was performed for the BFGD dose distribution using the NIPAM dose distribution as reference. The results of this comparison are shown in Fig. 4, where 99.98\% of the points meet the gamma index criterion.

\section{4. $1 D$ gamma analysis in regions with large deviations}

The 2D gamma distributions clearly have some regions that do not satisfy the passing criterion, which are depicted as red areas in Figs. 3 and 4 and correspond to regions with high gradient dose. In order to investigate the largest deviations between dose distributions, profiles through that areas were analyzed. Considering the red zones observed in 2D gamma test with MC as reference (Fig. 3), 1D gamma analysis was performed for profiles at $\mathrm{y}=-10 \mathrm{~mm}$ (Fig. 5).

In these types of figures, two different results are shown. First, the relative dose profiles of the different methods to be compared are represented. The reference distribution is plotted with a dashed line and the contrasted distribution with a continuous line. In these profiles, there is a central region with a higher dose corresponding to the added contribution of the four fields used in the irradiation of the dosimeters. On the external regions, the contribution of two fields is mainly present, resulting in a lower relative dose than the 

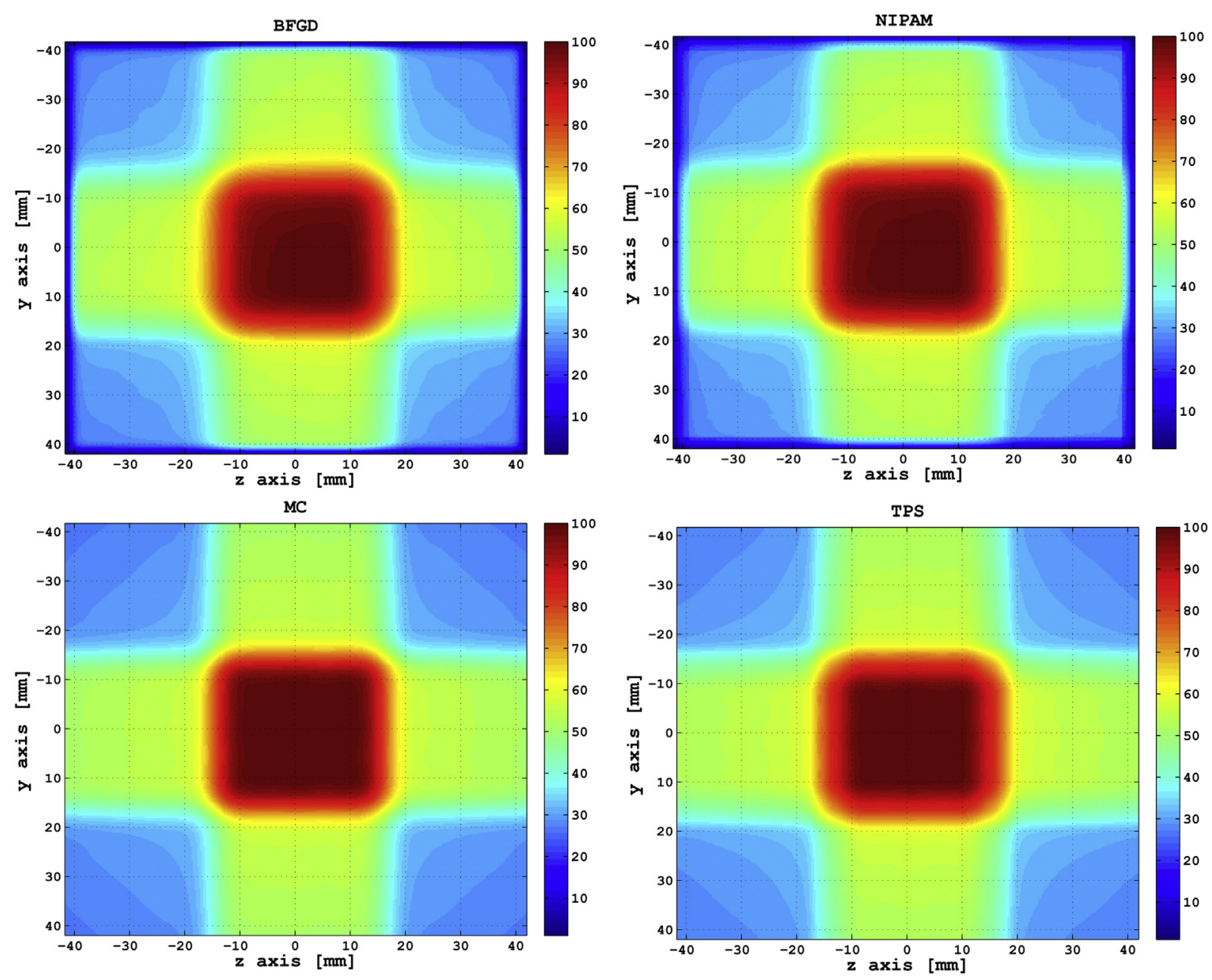

Fig. 2. Relative dose distributions with BFGD (top left), NIPAM (top right), MC (bottom left), and TPS (bottom right).

central region. In addition, high-gradient dose regions are present in the superimposition of the fields. Secondly, gamma index values multiplied by a factor of 100 are represented by triangles in these figures. In this case, those points that satisfy the passing criteria are plotted in green and the ones that do not fulfill these criteria are shown in red.

As could be observed in Fig. 5, gamma values around $\mathrm{z}=+10 \mathrm{~mm}$ are $>1$ for BFGD and NIPAM gamma test. The BFGD gamma profile presents a smaller number of accepted points (68.05\%) than the NIPAM gamma profile (85.94\%) and also have $\gamma>$ 1 values around $z=+10 \mathrm{~mm}$, in concordance with Fig. 3. The TPS gamma profile has a pass rate of $94.57 \%$, presenting rejected points around $\mathrm{z}= \pm 12 \mathrm{~mm}$, also in concordance with the 2D gamma analysis.

Regarding the 2D gamma test between both gel dosimetry measurements (Fig. 4), only a few points do not pass the criteria. Therefore, a 1D gamma analysis was carried out through profile $\mathrm{y}=-13 \mathrm{~mm}$ (Fig. 6). The acceptance rate is $98.08 \%$ and only $\gamma$ values around $\mathrm{z}=-13 \mathrm{~mm}$ are $>1$, in agreement with the 2D gamma analysis.

\subsection{On-axis gamma analysis}

A 1D gamma test was performed with the MC dose distribution as reference. The resulting profiles obtained at $\mathrm{y}=0 \mathrm{~mm}$ are shown in Fig. 7. It is evident from the figure that $\gamma<1$ values were obtained for the three systems in the central region ( $z$ between -8 and $+8 \mathrm{~mm}$ ). These results are of great importance, because they indicate that a homogeneous dose has been delivered to the target volume. Once again, the regions where a high-dose gradient exists are the ones presenting gamma indices that do not meet the passing criterion. Despite these regions, in the worst case, $96.49 \%$ of the analyzed points meet the passing criterion. As mentioned earlier, the useless dosimeter regions result in increasing the values of $\gamma$ index beyond $\pm 35 \mathrm{~mm}$.

Finally, both gel dosimetry measurements were compared (Fig. 8) and every point of the useful region (between $z=-35$ and $+35 \mathrm{~mm}$ ) of the dosimeters satisfies the passing criterion.

As mentioned in the 2D gamma analysis, an asymmetric dose distribution is observed in Fig. 7 when compared with MC simulations. In both gel measurements, the asymmetry becomes evident if the dose profiles at $\mathrm{z}$ values between -8 and $-12 \mathrm{~mm}$ are compared with those between $\mathrm{z}=8$ and $12 \mathrm{~mm}$.

There are different reasons that could lead to an asymmetric dose distribution, the main ones would be, the preparation method of the dosimeters, the preparation and nature of the phantoms and vessels for the dosimeters, the analytical methods used for their characterization, and the positioning or alignment 

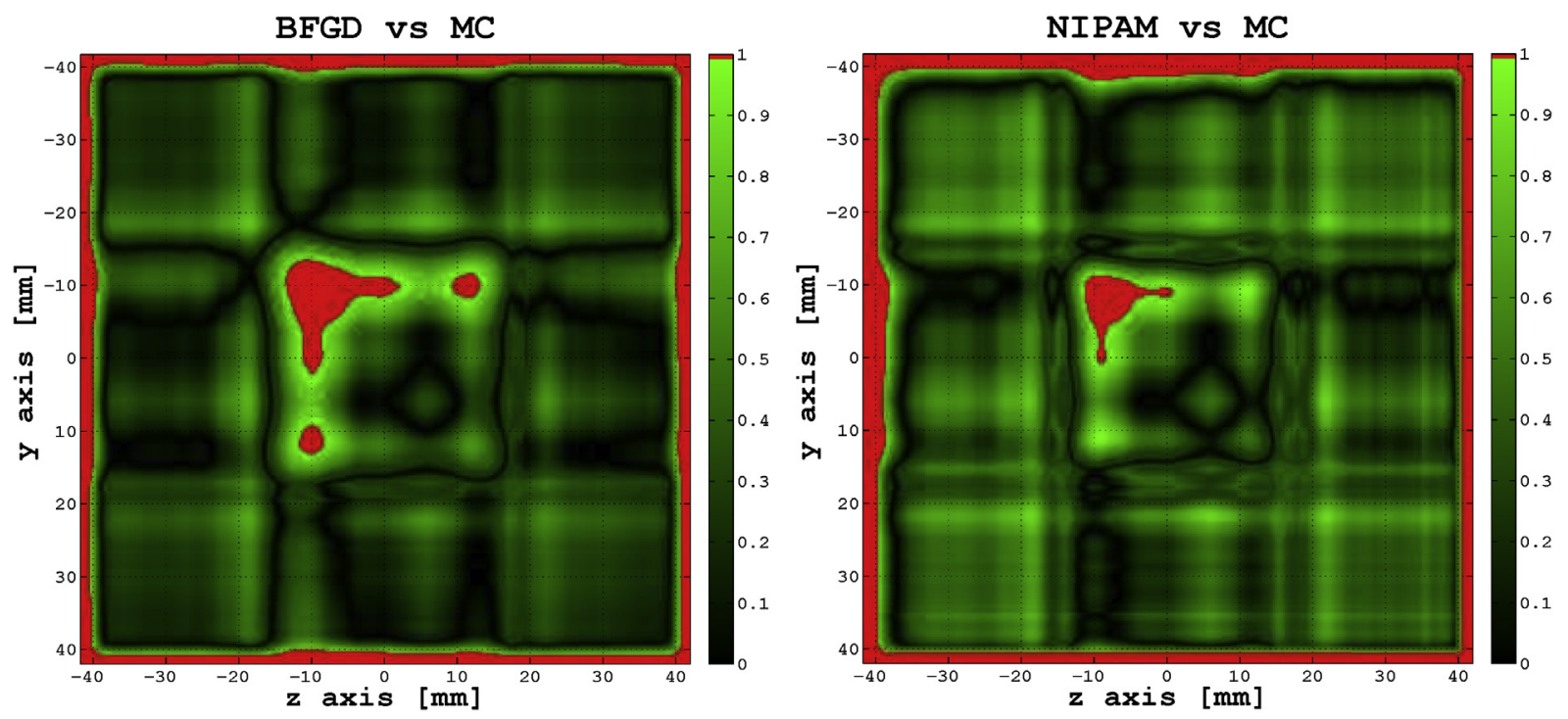

TPS vs MC

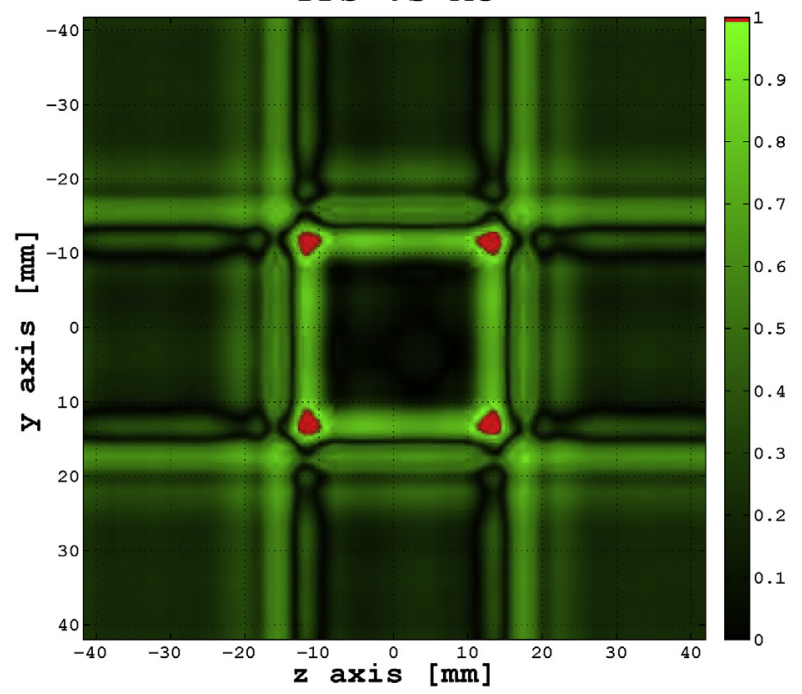

Fig. 3. Two-dimensional gamma analysis of BFGD (top left), NIPAM (top right), and TPS (bottom) dose distributions considering MC dose distribution as reference.

during their irradiation. Because of the characteristics of the preparation method, only homogeneous materials can be obtained. Therefore, an asymmetry caused by this preparation method or the characteristics of the materials used in the dosimeters is negligible. Furthermore, the same preparation and analytical methods were used in previous studies (Vedelago et al., 2014), but with a different irradiation configuration, and no asymmetric result has been observed. In regard to the optical method used for the analysis of the dosimeters, the same method was applied to different materials and setups observing no asymmetric behavior (Mattea et al., 2015). Consequently, the main reason for the asymmetry observed in this study could be related to the irradiation configuration and a possible misalignment of the four irradiation fields.

\subsection{Off-axis gamma analysis}

In order to assess the dosimetric system quantification in regions analogous to organs at risk in clinical uses, for example, at $\mathrm{y}=\mathrm{z}=30 \mathrm{~mm}$, where no direct irradiation has been made, 1D gamma tests were performed for profiles at $\mathrm{z}=30 \mathrm{~mm}$. The results obtained in these tests are shown in Figs. 9 and 10. In order to make these figures comparable to Figs. 7 and 8, the relative dose axis scale was maintained.

Results similar to the ones presented for $\mathrm{y}=0 \mathrm{~mm}$ were obtained, proving the consistency of the four dosimetric systems. It is worth mentioning that all points meet the passing criterion in these profiles.

\subsection{Variation of $2 \mathrm{D}$ gamma index parameters}

In the presented results, a low-tolerance ( $1 \mathrm{~mm}$ and $2 \%$ ) gamma test was performed. Nevertheless, the typical values in a clinical environment vary from $3 \mathrm{~mm}$ and $3 \%$ to $3 \mathrm{~mm}$ and $7 \%$ (Depuydt et al., 2002). Therefore, a sensitivity analysis of these parameters was performed, using different combinations of DTA and DD values. The results of this analysis are summarized in Fig. 11 and Table 1.

In the variable analysis presented in Fig. 11, the reference values of DTA and DD were set at $1 \mathrm{~mm}$ and $2 \%$, respectively. A variation in each of these parameters of $\pm 50 \%$ was made, keeping the remaining 


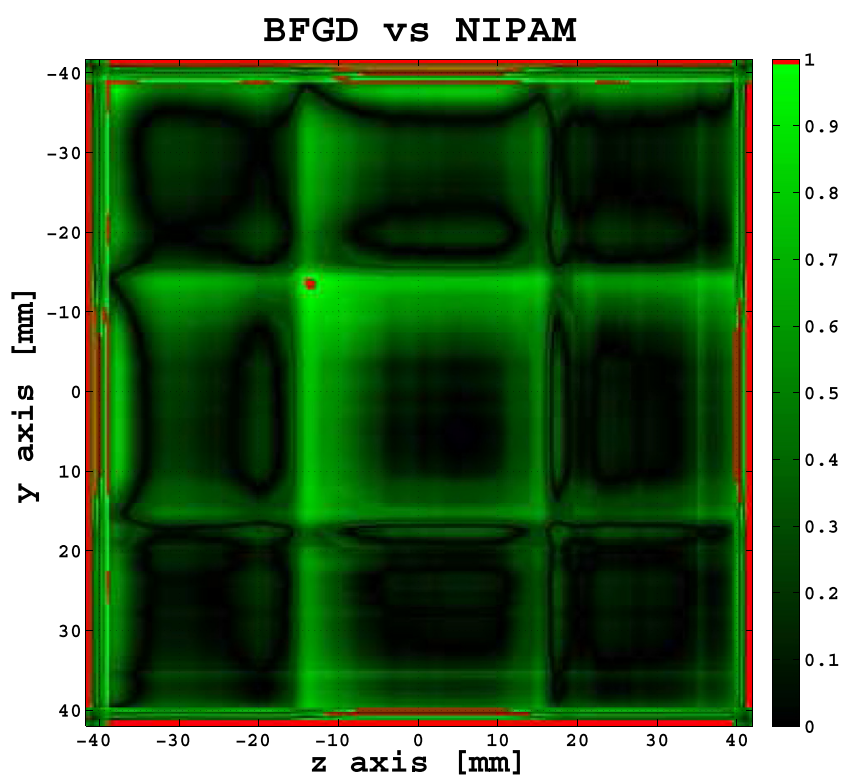

Fig. 4. Two-dimensional gamma analysis of BFGD considering NIPAM dose distribution as reference.

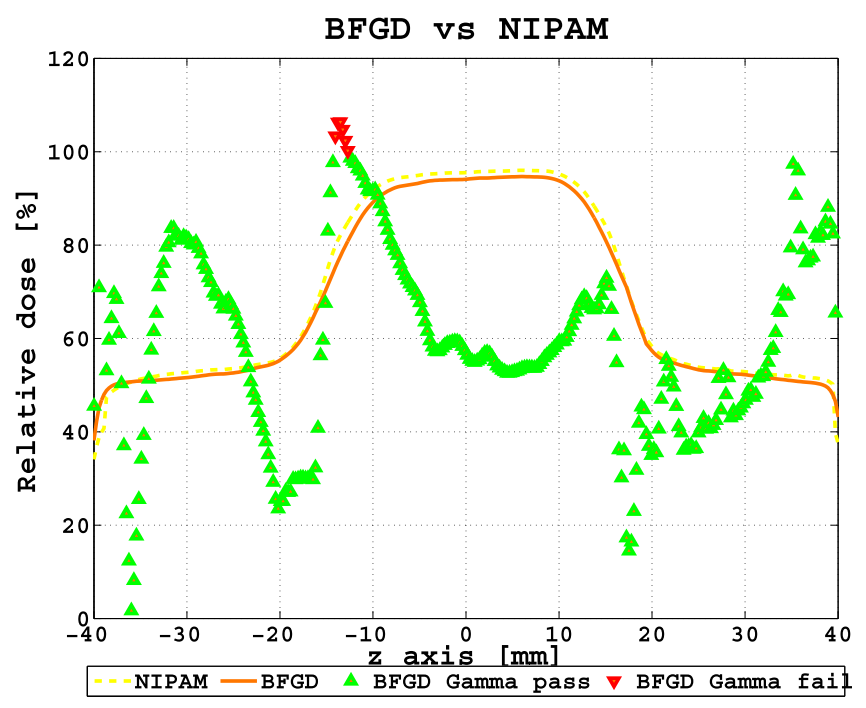

Fig. 6. One-dimensional gamma test for $\mathrm{y}=-13 \mathrm{~mm}$ of BFGD dose distribution considering NIPAM dose distribution as reference. For visualization purposes and for a direct comparison, the values of $\gamma$ were multiplied by 100 .
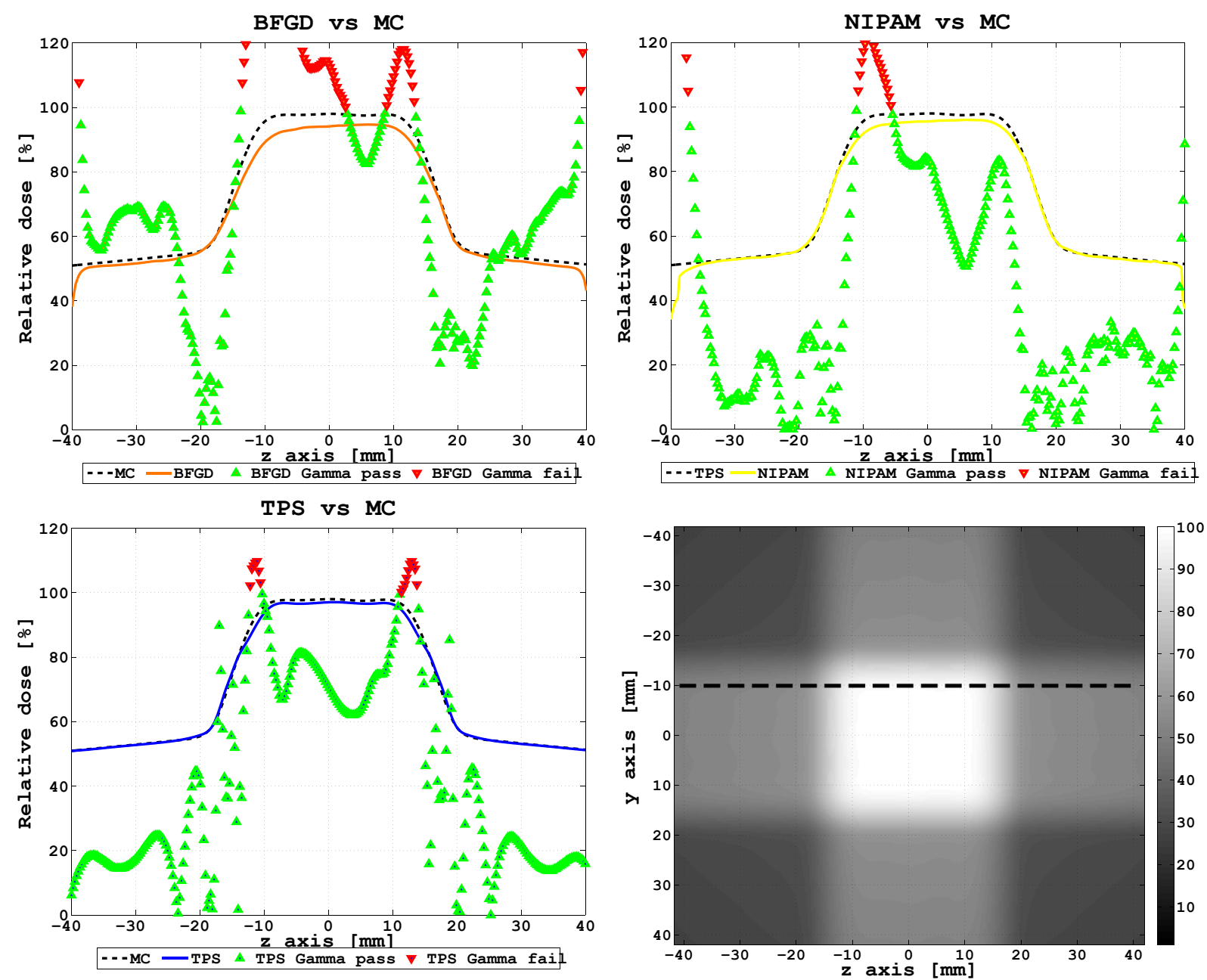

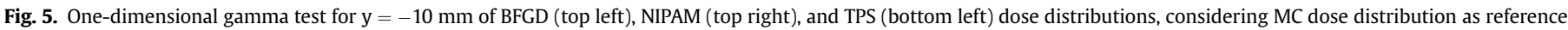

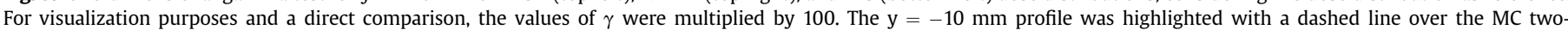
dimensional dose distribution (bottom right). 

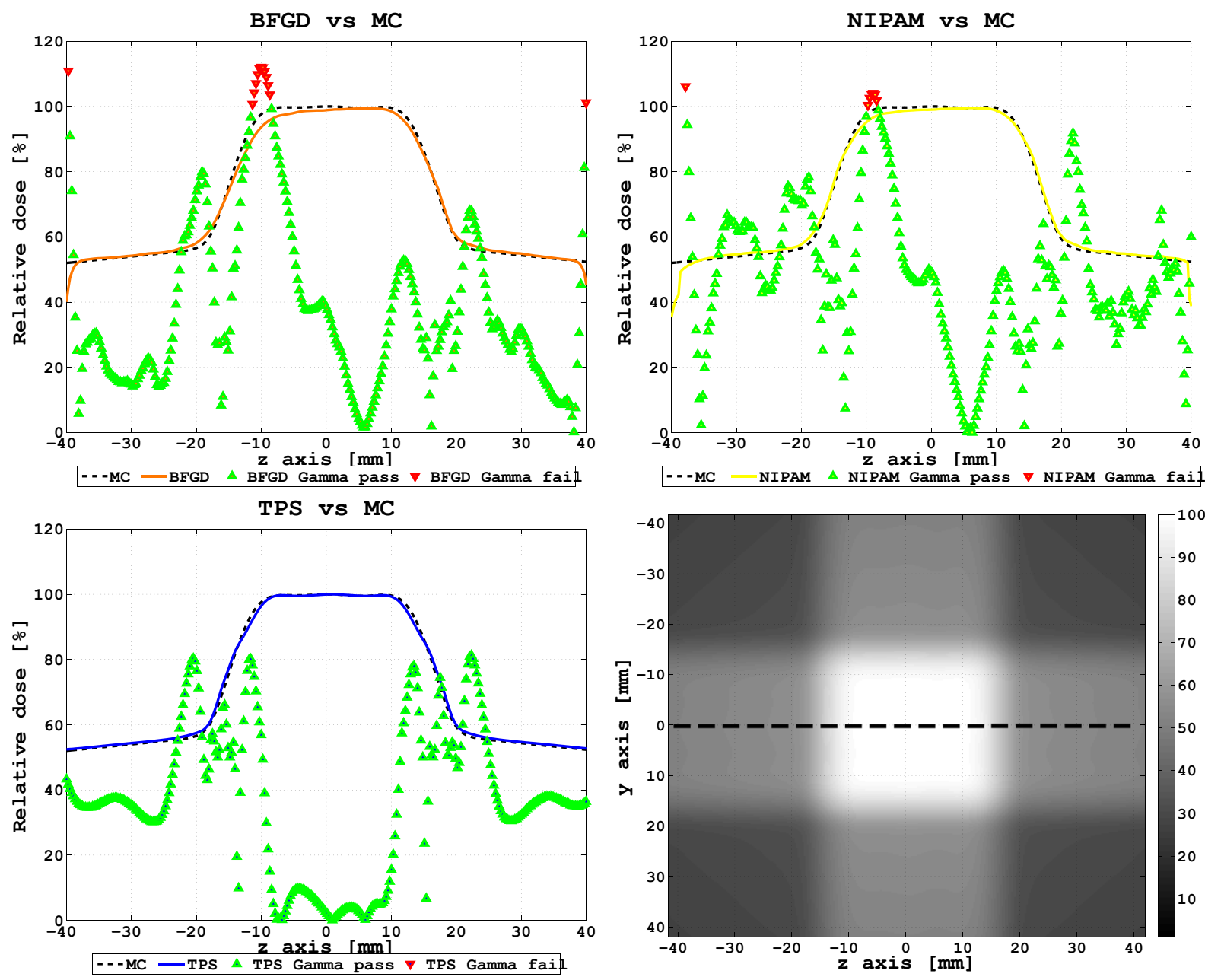

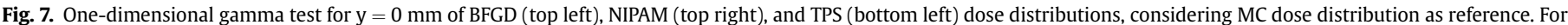

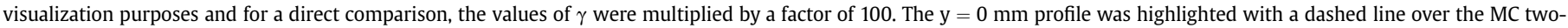
dimensional dose distribution (bottom right).

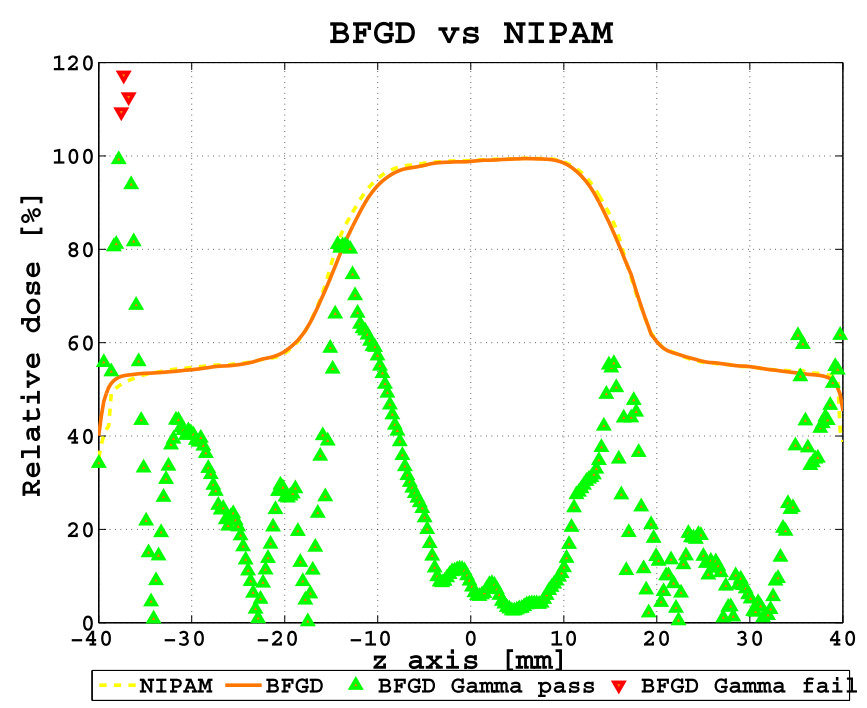

Fig. 8. One-dimensional gamma test for $\mathrm{y}=0 \mathrm{~mm}$ of BFGD dose distribution considering NIPAM dose distribution as reference. For visualization purposes and for a direct comparison, the values of $\gamma$ were multiplied by 100 . one unchanged, to reveal the influence of each one of them in the final percentage of accepted points. In addition, both parameters varied simultaneously to check if DTA and DD are independent.

From the results of this case, it is clear that the most influential parameter is DD and that there is a slight combination of effects of the influence of both variables when they are simultaneously varied. Furthermore, from the results for DTA $>1.5 \mathrm{~mm}$ and DD $>3 \%$, $>99.85 \%$ of the points were accepted in all the dosimeters investigated in this study.

The complete analytical method used in this study has an uncertainty on the dose value of $1-2 \%$, which limits the minimum DD that can be used in gamma index method. For DD $<1 \%$, there is no way to discriminate if there is a difference in the dosimetric systems or if the uncertainty of each dosimetric system is leading to gamma indices $>1$. In addition, DTA $<1 \mathrm{~mm}$ implies using $<4$ pixels around the point of interest for the gamma index calculation. Therefore, if less pixels are considered, noise in the image acquisition method could produce a large variation in the gamma indices. Because of these reasons and considering the results from Fig. 11, the most strict set of parameters that is still reasonable considering the available analytical techniques for this study is the one selected in the comparison study: DTA of $1 \mathrm{~mm}$ and DD of $2 \%$. This final analysis can be observed for each dosimeter in Table 1. 

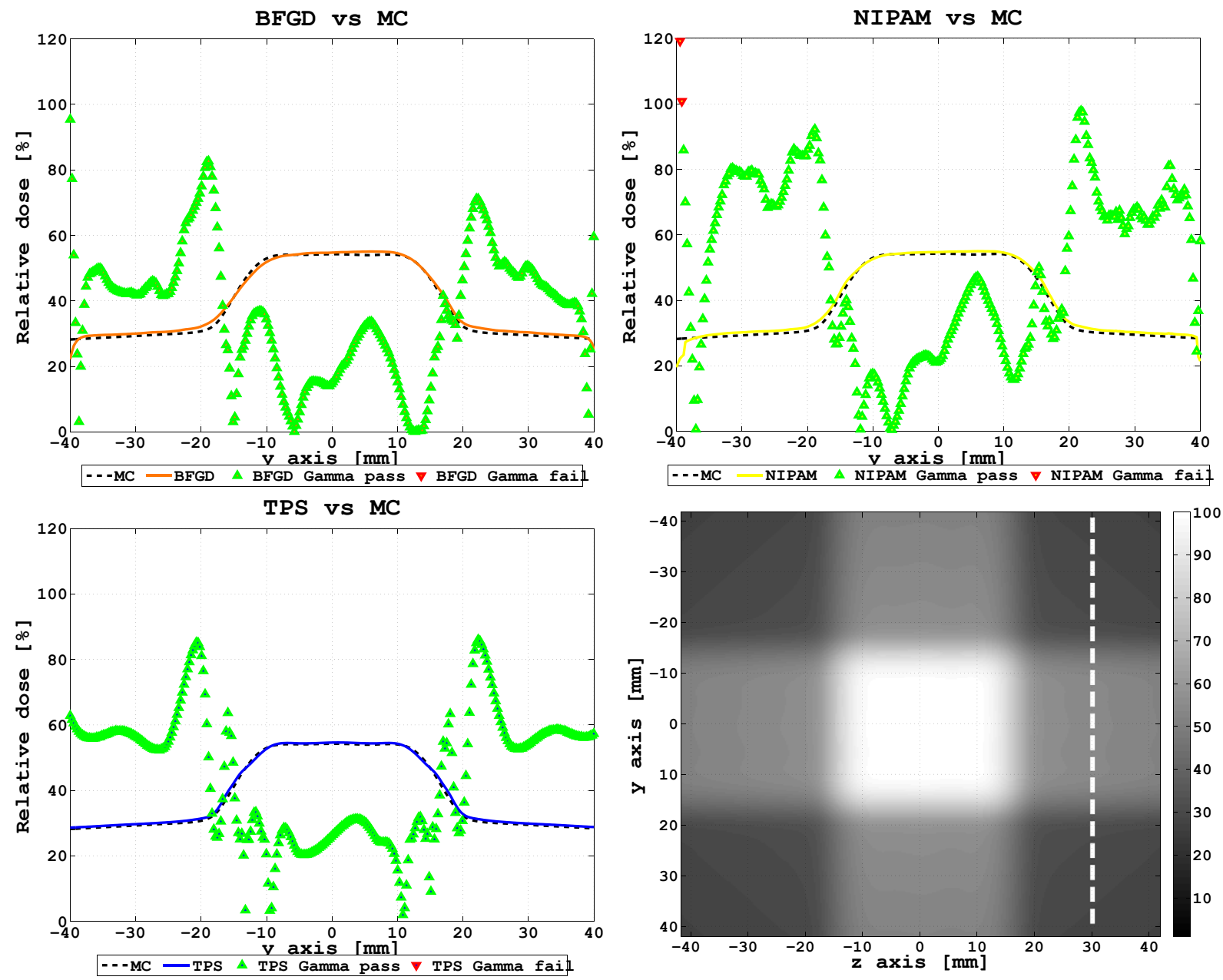

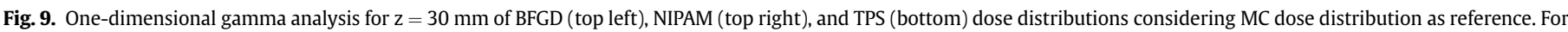

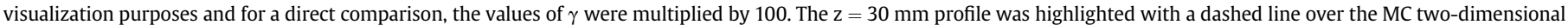
dose distribution (bottom right).

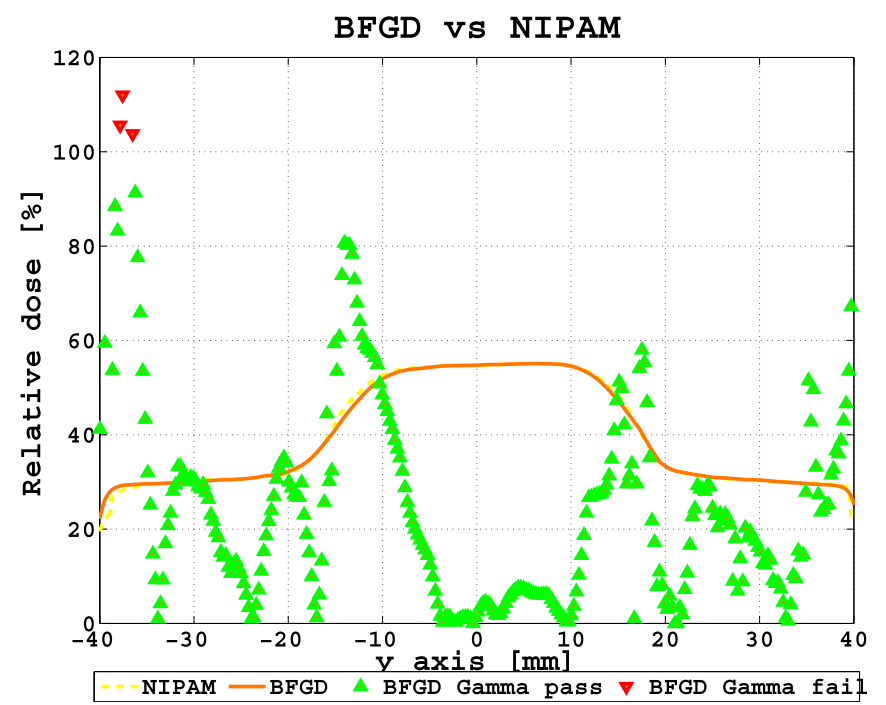

Fig. 10. One-dimensional gamma analysis for $\mathrm{z}=30 \mathrm{~mm}$ of BFGD dose distribution considering NIPAM dose distribution as reference. For visualization purposes and for a direct comparison, the values of $\gamma$ were multiplied by 100 .

\section{Conclusions}

A low-tolerance gamma index test with a DTA of $1 \mathrm{~mm}$ and DD of $2 \%$ was performed, comparing gel dosimetry measurements irradiated with a 6-MV photon beam with MC simulations and TPS calculations. Two different types of gel dosimeters were studied: BFGD and a NIPAM-based polymer gel dosimeter. An excellent agreement among the different methods was observed, where at least $98 \%$ of the analyzed points in every dosimetric system met the gamma index passing criterion. From these results, it was proved that gel dosimetry combined with optical transmission analysis represents a valuable tool for $\mathrm{QA}$ in tissue equivalent detectors. Furthermore, as gel dosimetry is a complete independent experimental method, it should be considered a potential tool for TPS validations.

Finally, the water equivalence in terms of absorption/scattering of ionizing radiation, of both BFGD and NIPAM dosimeters, was showed with the concordance of their dose distributions with TPS and MC ones, which were calculated in water. 

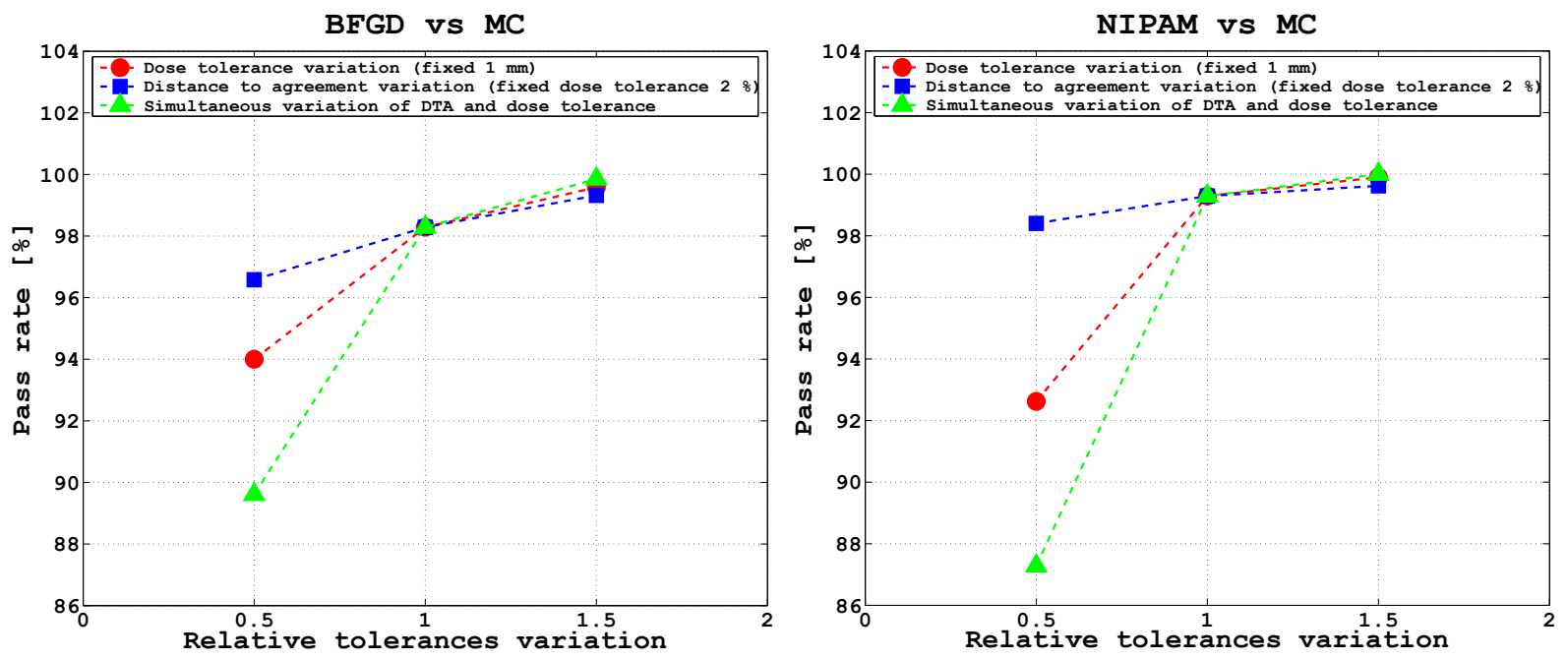

Fig. 11. DTA and DD influence in the percentage of accepted points in a two-dimensional gamma index analysis.

Table 1

Percentage of accepted points in the gamma index analysis for different DTA and DD values.

\begin{tabular}{|c|c|c|c|c|}
\hline Test distribution & Reference distribution & DTA [mm] & DD [\%] & Acceptance $(\gamma<1)[\%]$ \\
\hline NIPAM & MC & 1 & 1 & 92.62 \\
\hline BFGD & MC & 1 & 1 & 94.00 \\
\hline TPS & MC & 1 & 1 & 96.43 \\
\hline BFGD & NIPAM & 1 & 1 & 99.84 \\
\hline NIPAM & MC & 1 & 2 & 99.29 \\
\hline BFGD & MC & 1 & 2 & 98.28 \\
\hline TPS & MC & 1 & 2 & 99.56 \\
\hline BFGD & NIPAM & 1 & 2 & 99.98 \\
\hline NIPAM; BFGD; TPS & MC & 3 & 3 & 100.00 \\
\hline BFGD & NIPAM & 3 & 3 & 100.00 \\
\hline
\end{tabular}

\section{Acknowledgments}

This study was partially financed by CONICET via the Project ESPORA I - PIP 11220130100658CO, PIP 112-20110101029, and PIP 114-20090100398, and by FONCyT via the projects PICT 2011-0654 Res 140/12 and PICT 2008-0398 ANPCyT.

The authors would like to thank Universidad Nacional (UNA), Heredia, Costa Rica, for the financial support (JB-C 0612-2014) of the PhD studies of D. Chacón.

The authors are also grateful to the Masters Program in Medical Physics of Universidad de La Frontera, for supporting this study.

\section{References}

Baldock, C., Harris, P., Piercy, A., Healy, B., 2001. Experimental determination of the diffusion coefficient in two-dimensions in ferrous sulphate gels using the finite element method. Australas. Phys. Eng. Sci. Med. 24 (1), 19-30. http://dx.doi.org 10.1007/BF03178282.

Baldock, C., De Deene, Y., Doran, S., Ibbott, G., Jirasek, A., Lepage, M., McAuley, K. Oldham, M., Schreiner, L., 2010. Polymer gel dosimetry. Phys. Med. Biol. 55 (5) R1-R63. http://dx.doi.org/10.1088/0031-9155/55/5/R01.

Baró, J., Sempau, J., Fern_andez-Varea, J.M., Salvat, F., 1995. PENELOPE: an algorithm for Monte Carlo simulation of the penetration and energy loss of electrons and positrons in matter. Nucl. Instrum. Methods Phys. Res. B 100 (1), 31-46. http:// dx.doi.org/10.1016/0168-583X(95) 00349-5.

Ceberg, S., Gagne, I., Gustafsson, H., Scherman, J.B., Korreman, S.S., KjaerKristoffersen, F., Hilts, M., Bäck, S._A.J., 2010. RapidArc treatment veryfication in 3D using polymer gel dosimetry and Monte Carlo simulation. Phys. Med. Biol. 55 (17), 4885. http://dx.doi.org/10.1088/0031-9155/55/17/001.

Chang, Y.J., Hsieh, B.T., Liang, J.A., 2011. A systematic approach to determine optima composition of gel used in radiation therapy. Nucl. Instrum. Methods Phys. Res. Sect. A Accel. Spectrom. Detect. Assoc. Equip. 652 (1), 783-785. http:// dx.doi.org/10.1016/j.nima.2010.09.097.
Chang, Y.-J., Lin, J.-Q., Hsieh, B.-T., Yao, C.-H., Chen, C.-H., 2014. Dose evaluation of an NIPAM polymer gel dosimeter using gamma index. Radiat. Phys. Chem. 104, 180-187. http://dx.doi.org/10.1016/j.radphyschem.2013.11.031.

Chiu, C.-Y., Tsang, Y.-W., Hsieh, B.-T., 2014. N-isopropylacrylamide gel dosimeter to evaluate clinical photon beam characteristics. Appl. Radiat. Isotopes 90, 245-250. http://dx.doi.org/10.1016/j.apradiso.2014.04.015.

da Silveira, M.A., Pavoni, J.F., Salmon, C.E.G., Baffa, O., 2014. Tridimensional dosimetry for prostate IMRT treatments using MAGIC-f gel by MRI. Radiat. Meas. 71, 369-373. http://dx.doi.org/10.1016/j.radmeas.2014.07.011.

De Deene, Y, De Wagter, C., Van Duyse, B., Derycke, S, De Neve, W., Achten, E, 1998. Three-dimensional dosimetry using polymer gel and magnetic resonance imaging applied to the verification of conformal radiation therapy in head-andneck cancer. Radiother. Oncol. 48 (3), 283-291. http://dx.doi.org/10.1016/ S0167-8140(98)00087-5.

Depuydt, T., Van Esch, A., Huyskens, D.P., 2002. A quantitative evaluation of IMRT dose distributions: refinement and clinical assessment of the gamma evaluation. Radiother. Oncol. 62 (3), 309-319. http://dx.doi.org/10.1016/S01678140(01)00497-2.

Deshpande, S., Vial, P., Holloway, L., 2011. 2-D radiation therapy dosimetry using EPIDs: dose response variation between 3 siemens electronic portal imaging devices (EPIDs). Radiat. Meas. 46 (12), 1916-1919. http://dx.doi.org/10.1016/ j.radmeas.2011.08.006

Devic, S., 2011. Radiochromic film dosimetry: past, present, and future. Phys. Medica 27 (3), 122-134. http://dx.doi.org/10.1016/j.ejmp.2010.10.001.

Gambarini, G., Agosteo, S., Altieri, S., Bortolussi, S., Carrara, M., Gay, S., Nava, E., Petrovich, C., Rosi, G., Valente, M., 2007. Dose distributions in phantoms irradiated in thermal columns of two difierent nuclear reactors. Radiat. Prot. Dosim. 126 (1-4), 640-644. http://dx.doi.org/10.1093/rpd/ncm181.

Gupta, B., Gomathy, K., 1974. Consistency of ferrous sulphate-benzoic acid-xylenol orange dosimeter. Int. J. Appl. Radiat. Isotopes 25 (11), 509-513. http:/ dx.doi.org/10.1016/0020-708X(74)90077-5.

Harris, P., Piercy, A., Baldock, C., 1996. A method for determining the diffusion coeffcient in Fe (II/III) radiation dosimetry gels using finite elements. Phys. Med. Biol. 41 (9), 1745. http://dx.doi.org/10.1088/0031-9155/41/9/013.

Hassani, H., Nedaie, H.A., Zahmatkesh, M.H., Shirani, K., 2014. A dosimetric study of small photon fields using polymer gel and Gafchromic EBT films. Med. Dosim. 39 (1), 102-107. http://dx.doi.org/10.1016/j.meddos.2013.10.007. 
Huet, C., Dagois, S., Derreumaux, S., Trompier, F., Chenaf, C., Robbes, I., 2012. Characterization and optimization of EBT2 radiochromic films dosimetry system for precise measurements of output factors in small fields used in radiotherapy. Radiat. Meas. 47 (1), 40-49. http://dx.doi.org/10.1016/ j.radmeas.2011.10.020.

Jirasek, A., Hilts, M., McAuley, K., 2010. Polymer gel dosimeters with enhanced sensitivity for use in X-ray CT polymer gel dosimetry. Phys. Med. Biol. 55 (18), 5269. http://dx.doi.org/10.1088/0031-9155/55/18/002.

Kairn, T., Taylor, M., Crowe, S., Dunn, L., Franich, R., Kenny, J., Knight, R., Trapp, J., 2012. Monte Carlo verification of gel dosimetry measurements for stereotactic radiotherapy. Phys. Med. Biol. 57 (11), 3359-3369. http://dx.doi.org/10.1088/ 0031-9155/57/11/3359.

Keall, P., Baldock, C., 1999. A theoretical study of the radiological properties and water equivalence of Fricke and polymer gels used for radiation dosimetry. Australas. Phys. Eng. Sci. Med. 22 (3), 85-91. http://europepmc.org/abstract/ med/10816765.

Kelly, R., Jordan, K., Battista, J., 1998. Optical CT reconstruction of 3D dose distributions using the ferrous-benzoic-xylenol (FBX) gel dosimeter. Med. Phys. 25 (9), 1741-1750. http://dx.doi.org/10.1118/1.598356.

Knöös, T., 2015. QA procedures needed for advanced RT techniques and its impact on treatment outcome. J. Phys. Conf. Ser. 573, 12001-12008. http://dx.doi.org/ 10.1088/1742-6596/573/1/012001. IOP Publishing.

Knöös, T., Ceberg, C., Weber, L., Nilsson, P., 1994. The dosimetric verification of a pencil beam based treatment planning system. Phys. Med. Biol. 39 (10), 1609. http://dx.doi.org/10.1088/0031-9155/39/10/007.

Low, D.A., Harms, W.B., Mutic, S., Purdy, J.A., 1998. A technique for the quantitative evaluation of dose distributions. Med. Phys. 25 (5), 656-661. http://dx.doi.org/ $10.1118 / 1.598248$

Mariani, M., Vanossi, E., Gambarini, G., Carrara, M., Valente, M., 2007. Preliminary results from a polymer gel dosimeter for absorbed dose imaging in radiotherapy. Radiat. Phys. Chem. 76 (8), 1507-1510. http://dx.doi.org/10.1016/ j.radphyschem.2007.02.080.

Maryanski, M., Schulz, R., Ibbott, G., Gatenby, J., Xie, J., Horton, D., Gore, J., 1994 Magnetic resonance imaging of radiation dose distributions using a polymergel dosimeter. Phys. Med. Biol. 39 (9), 1437-1455. http://dx.doi.org/10.1088/ 0031-9155/39/9/010.

Mattea, F., Strumia, M. Valente, M., 2013. Characterization of a polymer ge dosimetry system based on n-isopropylacrylamide and n-n'methylenebisacrylamide. In: Proceedings of X Latin American Symposium on Nuclear Physics and Applications, Uruguay, Vol. PoS (X LASNPA), Proceedings of Science, p. 080. http://pos.sissa.it/archive/conferences/194/080/X\%20LASNPA 080.pdf.

Mattea, F., Romero, M.R., Vedelago, J., Quiroga, A., Valente, M., Strumia, M.C., 2015. Molecular structure effects on the post irradiation diffusion in polymer gel dosimeters. Appl. Radiat. Isotopes 100, 101-107. http://dx.doi.org/10.1016/ j.apradiso.2015.03.007.

Mohan, R., Chui, C., Lidofsky, L., 1985. Energy and angular distributions of photons from medical linear accelerators. Med. Phys. 12 (5), 592-597. http://dx.doi.org
$10.1118 / 1.595680$

Poppe, B., Blechschmidt, A., Djouguela, A., Kollhoff, R., Rubach, A., Willborn, K.C. Harder, D., 2006. Two-dimensional ionization chamber arrays for IMRT plan verification. Med. Phys. 33 (4), 1005-1015. http://dx.doi.org/10.1118/1.2179167. Schreiner, L., 2004. Review of Fricke gel dosimeters. J. Phys. Conf. Ser. 3, 9-21. http://dx.doi.org/10.1088/1742-6596/3/1/003. IOP Publishing.

Sempau, J., Andreo, P., 2006. Configuration of the electron transport algorithm of PENELOPE to simulate ion chambers. Phys. Med. Biol. 51 (14), 3533-3548. http://dx.doi.org/10.1088/0031-9155/51/14/017.

Sempau, J., Fernández-Varea, J.M., Acosta, E., Salvat, F., 2003. Experimental benchmarks of the Monte Carlo code PENELOPE. Nucl. Instrum. Methods Phys. Res. B 207 (2), 107-123. http://dx.doi.org/10.1016/S0168-583X(03)00453-1.

Senden, R.J., De Jean, P., McAuley, K., Schreiner, L., 2006. Polymer gel dosimeters with reduced toxicity: a preliminary investigation of the NMR and optical doseresponse using different monomers. Phys. Med. Biol. 51 (14), 3301-3314. http:// dx.doi.org/10.1088/0031-9155/51/14/001.

Spezi, E., Lewis, D., Smith, C., 2002. A DICOM-RT-based toolbox for the evaluation and verification of radiotherapy plans. Phys. Med. Biol. 47 (23), 4223. http:// dx.doi.org/10.1088/0031-9155/47/23/308.

Valente, M., Vedelago, J., 2013. Design of an integral radiation dosimetry system optimized for modern medical applications. In: Proceedings of X Latin American Symposium on Nuclear Physics and Applications, Uruguay, Vol. PoS (X LASNPA), Proceedings of Science, p. 050. http://pos.sissa.it/archive/conferences/ 194/050/X\%20LASNPA 050.pdf.

Valente, M., Aon, E., Brunetto, M., Castellano, G., Gallivanone, F., Gambarini, G., 2007. Gel dosimetry measurements and Monte Carlo modeling for external radiotherapy photon beams: comparison with a treatment planning system dose distribution. Nucl. Instrum. Methods Phys. Res. Sect. A Accel. Spectrom. Detect. Assoc. Equip. 580 (1), 497-501. http://dx.doi.org/10.1016/j.nima.2007.05.243.

Vanossi, E., Carrara, M., Gambarini, G., Mariani, M., Valente, M., 2008. Study of polymer gel for dose imaging in radiotherapy. Radiat. Meas. 43 (2), 442-445. http://dx.doi.org/10.1016/j.radmeas.2008.01.012.

Vedelago, J., Quiroga, A., Valente, M., 2014. Characterization of ferric ions diffusion in Fricke gel dosimeters by using inverse problem techniques. Radiat. Eff. Defects Solids $169 \quad(10), \quad 845-854 . \quad$ http://dx.doi.org/10.1080 10420150.2014.958749.

Wendling, M., Zijp, L.J., McDermott, L.N., Smit, E.J., Sonke, J.-J., Mijnheer, B.J., van Herk, M., 2007. A fast algorithm for gamma evaluation in 3D. Med. Phys. 34 (5), 1647-1654. http://dx.doi.org/10.1118/1.2721657.

Wuu, C.-S., Xu, Y., 2011. 3-D dosimetry with optical CT scanning of polymer gels and radiochromic plastic dosimeter. Radiat. Meas. 46 (12), 1903-1907. http:/ dx.doi.org/10.1016/j.radmeas.2011.06.010.

Yao, C., Hsu, W., Hsu, S., Ma, P., Hsieh, B., Chang, Y., 2013. NIPAM polymer ge dosimetry for IMRT four-field box irradiation using optical-CT scanner. J. Phys. Conf. Ser. 444, 012030. http://dx.doi.org/10.1088/1742-6596/444/1/012030. IOP Publishing. 